\title{
EFEITO DO SILÍCIO E DO FÓSFORO NA DISPONIBILIDADE DE METAIS PESADOS DO SOLO PELO EXTRATOR MEHLICH-1 ${ }^{1}$
}

\author{
LILIAN APARECIDA PAIM ${ }^{2}$ \\ RUY CARVALHO ${ }^{3}$ \\ WALCLEÉ DE CARVALHO MELO ${ }^{3}$ \\ ANTÔNIO EDUARDO FURTINI NETO ${ }^{4}$
}

\begin{abstract}
RESUMO - Este trabalho foi desenvolvido em um solo contaminado por metais pesados de uma área de extração e industrialização de zinco pertencente à Companhia Mineira de Metais, em Três Marias, MG, com o objetivo de avaliar a eficiência do silício e do fósforo como agentes amenizadores da toxidez dos metais pesados. As amostras coletadas foram preparadas e incubadas em frascos de polietileno, com umidade equivalente a $60 \%$ do volume total de poros. Foram utilizados 25 tratamentos: cinco doses de silício $(0 ; 2.340 ; 6.040$;
\end{abstract}

9.860 e $\left.13.660 \mathrm{mg} \mathrm{dm}^{-3}\right)$ e cinco de fósforo $(0 ; 90 ; 180$; 360 e $720 \mathrm{mg} \mathrm{dm}^{-3}$ ), com quatro repetições, totalizando 100 unidades experimentais. Aos 30 e 60 dias, coletaram-se amostras de cada tratamento, submetidas a análises de pH em água e extrações simples por Mehlich-1. Os teores extraídos receberam influência do silício, do fósforo e do $\mathrm{pH}$. Os teores de $\mathrm{Zn}$ e $\mathrm{Cd}$, embora reduzidos, permaneceram acima dos níveis permitidos. $\mathrm{O} \mathrm{Pb}$ diminuiu influenciado pelo incremento de silício e fósforo a níveis inferiores aos permitidos.

TERMOS PARA INDEXAÇÃO: Silício, fósforo, metal pesado e pH.

\section{EFFECT OF SILICON AND PHOSPHORUS ON THE AVAILABILITY OF SOIL HEAVY METALS BY MEHLICH-1 EXTRACTOR}

\begin{abstract}
This work was developed on a soil contaminated by heavy metals from a zinc-extracting and industrializing area belonging to the Companhia Mineira de Metais at Tres Marias, Minas Gerais state, Brazil, with a view to evaluating the efficiency of silicon and phosphorus as ameliorating agents of heavy metal toxicity. The samples collected were prepared and incubated into polyethylene flasks, moisture equivalent to $60 \%$ of the total volume of pores. 25 treatments were utilized: five doses of silicon ( 0 ; $2.340 ; 6.040 ; 9.860$ and $13.660 \mathrm{mg} \mathrm{dm}^{-3}$ ) and five of
\end{abstract}

phosphorus $\left(0 ; 90 ; 180 ; 360\right.$ and $\left.720 \mathrm{mg} \mathrm{dm}^{-3}\right)$ with four replicates amounting to 100 experimental units. At 30 and 60 days, samples from each treatment were collected, submitted to water $\mathrm{pH}$ analysis and simple extraction by Mehlich-1. The extracted contents received greater influence from both silicon and phosphorous and at a lesser extent from $\mathrm{pH}$. $\mathrm{Zn}$ and $\mathrm{Cd}$ contents, although reduced, remained above the allowed levels. $\mathrm{Pb}$ decreased, influenced by the increase of silicon and phosphorus to level inferior to those permitted.

INDEX TERMS: Silicon, phosphorus, heavy metal and $\mathrm{pH}$.

\section{INTRODUÇÃO}

As atividades industriais podem representar perigosas fontes poluidoras, principalmente no que diz respeito à adição de metais pesados no solo. Contidos naturalmente em rochas, esses elementos não constitui- riam perigo ambiental, se não fossem explorados como minérios, se houvesse retrocesso no emprego de adubos, corretivos e, ainda, se fosse possível evitar a queima de combustíveis fósseis e os resíduos de industrialização e de mineração. No caso da extração e industrialização de zinco pela Companhia Mineira de Metais, a área se

\footnotetext{
1. Parte da dissertação de Mestrado da primeira autora.

2. Mestre em Agronomia - Agroquímica e Agrobioquímca, UNIVERSIDADE FEDERAL DE LAVRAS/UFLA, Caixa

Postal 37 - 37200-000 - Lavras, MG.

3. Professores do Departamento de Química/UFLA.

4. Professor do Departamento de Ciência do Solo/UFLA.
} 
encontra em avançado processo de degradação ambiental (Ribeiro Filho et al., 1999). Isso se deve ao despejo de dejetos no solo, incorporando ao sistema, além do zinco, metais como cádmio, chumbo e cobre, em teores superiores aos normalmente encontrados para solos. Estão também acima dos níveis permitidos pela Comunidade Econômica Européia, que são, em $\mathrm{mg} \mathrm{dm}^{-3}: 150$ para $\mathrm{Zn}, 3$ para $\mathrm{Cd}, 140$ para $\mathrm{Cu}$ e 50 para $\mathrm{Pb}$ (Chander \& Brookes, 1991, 1993), provocando, com o passar do tempo, uma completa descaracterização do solo. O resultado é um material disforme, uma lama, devido aos altos teores de metais.

Entre as diversas medidas amenizadoras para o problema da contaminação do solo por metais pesados, destacam-se a incorporação de matéria orgânica, por seu conhecido poder quelatizante dos cátions metálicos, principalmente o $\mathrm{Cu}$ (McBride, 1994; Gomes et al., 1997; Simão, 1999), a fosfatagem, que, além de fornecer fósforo a essas áreas, normalmente pobres nesse e em outros nutrientes, é capaz de imobilizar os metais por precipitação, formando fosfatos de $\mathrm{Cd}, \mathrm{Pb}, \mathrm{Cu}$ (Ayati \& Madsen, 2001) e Zn (Carvalho, 1999) e a correção de acidez por ação dos calcários. Essa última eleva o pH para uma faixa na qual a absorção desses metais pelas plantas se torna menor. O Cd, particularmente, é um elemento muito susceptível a mudanças de $\mathrm{pH}$ (Chlopecka et al., 1996), principalmente na rizosfera. Segundo Martinez \& Motto (2000), para Pb, Zn e $\mathrm{Cu}$, os valores de $\mathrm{pH} 5,2,6,2$ e 5,5, respectivamente, são limiares de toxidez em solos tropicais. Acima desses valores, tornam-se menos móveis e, portanto, pouco disponíveis no solo.

Considerando que praticamente inexistem pesquisas que relacionem a correção de acidez do solo pelo silício com teores de metais pesados, bem como avaliem o emprego do silício e do fósforo, conduziu-se este com o objetivo de avaliar a eficiência combinada do silício e do fósforo como agentes amenizadores de um solo contaminado por metais pesados, por meio de extrações simples pelo Mehlich-1.

\section{MATERIAL E MÉTODOS}

As amostras de solo foram provenientes de área de rejeito de uma unidade de extração e industrialização de zinco da Companhia Mineira de Metais, localizada no município de Três Marias, MG. A área, com aproximadamente 18 ha, encontra-se sem vegetação, em estágio avançado de degradação ambiental, devido à presença de elevados teores de $\mathrm{Zn}, \mathrm{Cd}, \mathrm{Cu}$ e $\mathrm{Pb}$ (Ribeiro Filho et al., 1999).

Essas amostras, após serem secas ao ar, foram passadas em peneira com malha de $2 \mathrm{~mm}$ de abertura. As análises químicas ( $\mathrm{pH}$ em água, $\mathrm{K}, \mathrm{Ca}, \mathrm{Mg}, \mathrm{H}+\mathrm{Al}$, $\mathrm{P}$ e carbono orgânico) foram realizadas conforme EMBRAPA $(1979,1997)$. Os teores de óxidos de Fe livres totais foram obtidos por meio de extrações sucessivas com ditionito-citrato-bicarbonato de sódio $\left(\mathrm{Fe}_{2} \mathrm{O}_{3} \mathrm{~d}\right)$ (Mehra \& Jackson, 1960); os teores dos óxidos totais $\left(\mathrm{SiO}_{2}, \mathrm{Al}_{2} \mathrm{O}_{3}, \mathrm{Fe}_{2} \mathrm{O}_{3}, \mathrm{TiO}_{2}\right.$ e $\left.\mathrm{P}_{2} \mathrm{O}_{5}\right)$, obtidos pelo ataque sulfúrico, foram determinados conforme Vettori (1969) com modificações de EMBRAPA (1997) e a capacidade máxima de adsorção de fósforo (CMAF) foi estimada conforme Syers et al. (1973).

Os experimentos foram conduzidos nos laboratórios do Departamento de Ciência do Solo e do Departamento de Química da Universidade Federal de Lavras, MG. A unidade experimental constou de um frasco de polietileno com capacidade para $7 \mathrm{dm}^{3}$, ocupado com $3,8 \mathrm{dm}^{3}$ de terra passada em peneira com malha de $2 \mathrm{~mm}$ de abertura. Todas as amostras foram submetidas à incubação após serem tratadas com doses de silício combinadas com doses de fósforo por um período total de 60 dias, sob nível de umidade equivalente a $60 \%$ do volume total de poros (Freire et al., 1980). As doses de silício $\left(\mathrm{CaSiO}_{3}\right.$ p.a. Vetec) foram $0 ; 2.340 ; 6.040$; 9.860 e $13.660 \mathrm{mg} \mathrm{dm}^{-3}$, estabelecidas por equação de regressão obtida com base em experimento prévio de incubação até a estabilização do $\mathrm{pH}$, o que ocorreu em 30 dias. As doses de fósforo $\left(\mathrm{Ca}\left(\mathrm{H}_{2} \mathrm{PO}_{4}\right)_{2} \cdot \mathrm{H}_{2} \mathrm{O}\right.$ p.a. Fluka) foram $0 ; 90 ; 180 ; 360$ e $720 \mathrm{mg} \mathrm{dm}^{-3}$, deduzidas da isoterma de Langmuir, construída com base em experimento prévio de determinação da capacidade máxima de adsorção de fósforo (CMAF), conforme Syers et al. (1973). Dessa maneira, os valores das doses oscilaram para mais e para menos em relação a uma dose central, suficiente para manter $0,2 \mathrm{mg} \mathrm{dm}^{-3}$ de fósforo na solução do solo (Roy et al., 1971). Como as fontes de silício e fósforo empregadas trouxeram o $\mathrm{Ca}^{+2}$ como cátion acompanhante, procedeu-se a um nivelamento do mesmo com cloreto de cálcio $\left(\mathrm{CaCl}_{2} \cdot 2 \mathrm{H}_{2} \mathrm{O}\right.$ p.a. Reagen) nos tratamentos afins.

$\mathrm{O}$ delineamento experimental utilizado foi $\mathrm{o}$ inteiramente casualizado, em esquema fatorial $5 \times 5$, com quatro repetições, totalizando 100 unidades experimentais.

Aos 30 e aos 60 dias após a aplicação das doses de silício e fósforo, foram retiradas amostras de cada tratamento. Elas foram, então, secas ao ar, passadas 
em peneira com malha de $2 \mathrm{~mm}$ de abertura e submetidas às análises químicas de $\mathrm{pH}$ em água na relação solo:água $1: 2,5$. Os metais $\mathrm{Zn}, \mathrm{Cd}, \mathrm{Pb}$ e $\mathrm{Cu}$ foram extraídos pelo extrator Mehlich-1 na relação solo:extrator 1:10 (Korcak \& Fanning, 1978; Abreu et al., 1995; EMBRAPA, 1997) e determinados por espectrofotometria de absorção atômica.

Concluída a análise de variância dos resultados obtidos, foram ajustadas equações de regressão polinomiais (aplicativo Sigma Plot) para as variáveis experimentais (pH, Cd, $\mathrm{Pb}, \mathrm{Cu}$, e $\mathrm{Zn}$ ) aos 30 e aos 60 dias, em função das doses de silício e de fósforo.

\section{RESULTADOS E DISCUSSÃO}

A influência das doses de silício e de fósforo sobre o $\mathrm{pH}$ aos 30 e 60 dias foi semelhante (Figura 1), ou seja, há um incremento do mesmo em função das doses de silício, pois com as doses de fósforo, o $\mathrm{pH}$ praticamente não diferiu do tratamento controle aos $30 \mathrm{di}-$ as, mas aos 60 dias, obtiveram-se valores de $\mathrm{pH}$ superior ao mesmo.

O máximo $\mathrm{pH}$, em torno de 7,5 aos 30 dias e cerca de 8,0 aos 60 dias, ocorreu quando aplicaram-se $8.030 \mathrm{mg} \mathrm{dm}^{-3}$ de silício, provavelmente porque os ânions $\mathrm{SiO}_{3}^{-2}$ resultantes da dissociação iônica do Ca$\mathrm{SiO}_{3}$ atuam como bases de Bronsted-Lowry, capturando protóns $\mathrm{H}^{+}$(acidez) dissociados na água do solo. Há evidências (Joly, 1966; Lindsay, 1979) de que a espécie $\mathrm{H}_{2} \mathrm{SiO}_{3}$, produto final da combinação do $\mathrm{SiO}_{3}{ }^{-2}$ com dois prótons $\mathrm{H}^{+}$, não se estabiliza como tal no solo. Ela tende a se combinar com uma molécula de água para se transformar em ácido monossilícico, $\mathrm{H}_{4} \mathrm{SiO}_{4}$, que é a forma de sílica solúvel nos solos na faixa de $\mathrm{pH} 4$ a 9 . Já o papel do fósforo na mudança do $\mathrm{pH}$ pode ser entendido de duas formas. Primeiro, por reação química de precipitação do ânion fosfato diácido $\left(\mathrm{H}_{2} \mathrm{PO}_{4}^{-}\right)$, originado da fonte de fósforo utilizada, com espécies do tipo $\mathrm{Cd}^{+2}, \mathrm{Zn}^{+2}, \mathrm{Cu}^{+2}$ ou $\mathrm{Pb}^{+2}$, diminuindo a atividade química e o poder tamponante de $\mathrm{pH}$ dessas como ácido de Lewis (Huheey et al., 1993), responsáveis pela elevada acidez das amostras de solo. Segundo, pela própria reação de adsorção de fósforo às superfícies dos minerais de argila (óxidos de $\mathrm{Fe}$ e $\mathrm{Al}$ ) presentes no solo, um processo de troca de ligantes do complexo de superfície em que hidroxilas $\left(\mathrm{OH}^{-}\right)$previamente coordenadas aos cátions $\mathrm{Fe}^{+3}$ ou $\mathrm{Al}^{+3}$ são deslocadas pelos íons $\mathrm{H}_{2} \mathrm{PO}_{4}^{-}$, formando um novo complexo de superfície (Hingston et al., 1972; Volkweiss \& Raij, 1977).
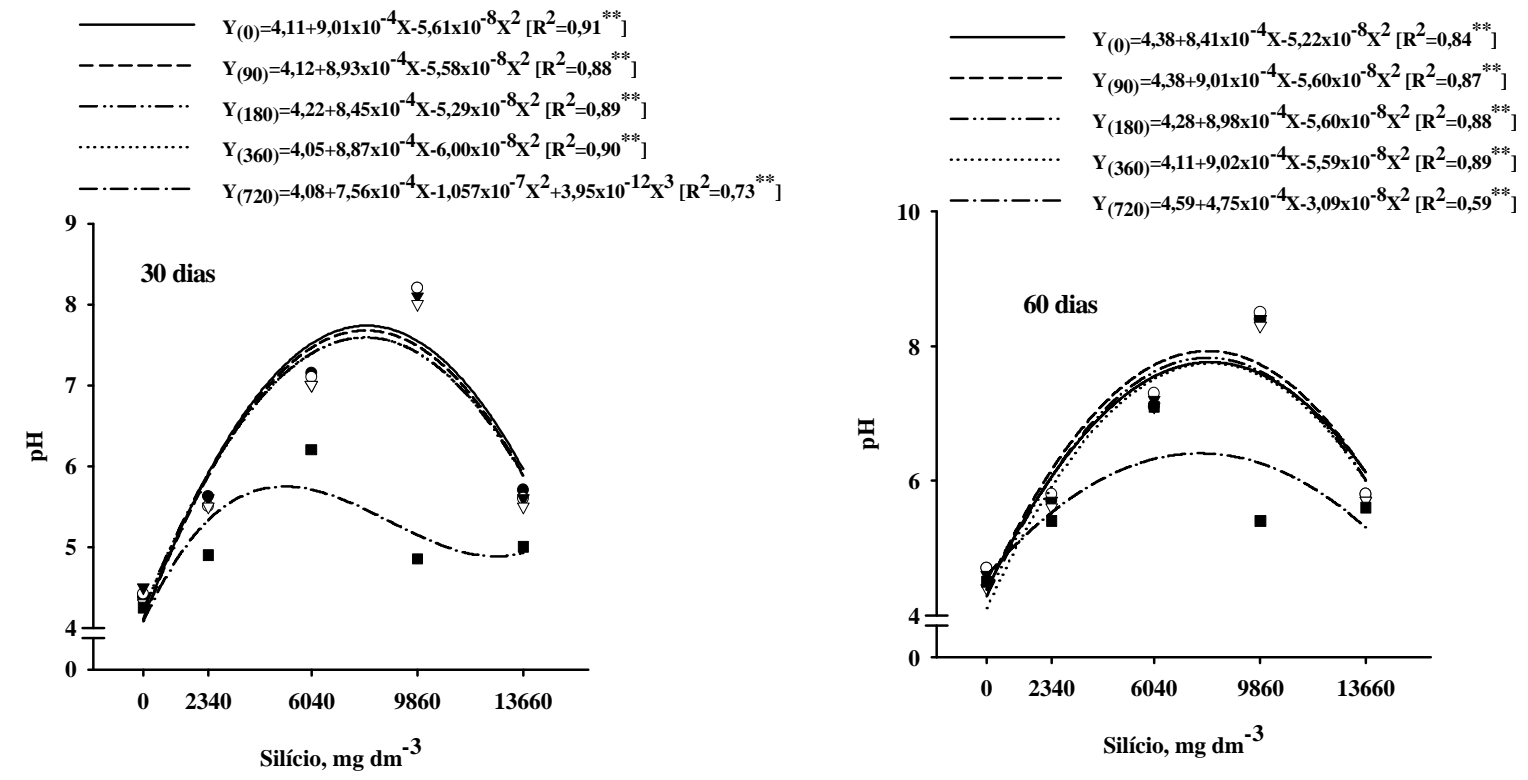

FIGURA 1 - Efeito das doses de silício e de fósforo $\left(\mathrm{mg} \mathrm{dm}^{-3}\right)$ no $\mathrm{pH}$ do solo contaminado por metais pesados, em duas diferentes épocas.

Ciênc. agrotec., Lavras. V.27, n.4, p.780-787, jul./ago., 2003 
Com a queda de $\mathrm{pH}$ em ambos os casos infere-se uma diminuição da atividade dos ânions $\mathrm{SiO}_{3}{ }^{-2}$ como bases, devido à precipitação, quando houve um crescimento brusco da dose de silício de 6.040 para 13.660 $\mathrm{mg} \mathrm{dm}^{-3}$. Como a diminuição de $\mathrm{pH}$ se deu até o valor 6,0 superior ao pH 4,6 original das amostras, é razoável admitir também que parte do silício precipitou-se juntamente com os metais pesados, reduzindo a sua capacidade tamponante e impedindo que o $\mathrm{pH}$ caísse abaixo de 6,0 .

Os maiores teores de chumbo extraído aos 30 e 60 dias (Figura 2) ocorreram no tratamento-controle (zero de silício e zero de fósforo), cerca de 112,6 e $83,4 \mathrm{mg} \mathrm{dm}^{-3}$ de $\mathrm{Pb}$, respectivamente. Um fato marcante é a relação inversa entre o crescimento das doses de silício e de fósforo e a diminuição da concentração de $\mathrm{Pb}$ nos extratos. Essa diminuição, que chegou a ser linear para algumas doses de fósforo aos 60 dias, pode ser explicada pela precipitação de fosfatos (Ayati \& Madsen, 2001) e silicatos de $\mathrm{Pb}$, os quais não foram solubilizados, mesmo quando em contato com os dois ácidos fortes do extrator, $\mathrm{HCl} \mathrm{e} \mathrm{H}_{2} \mathrm{SO}_{4}$. Pode-se observar também que as quantidades extraídas foram menores aos 60 dias que aos 30 dias, levando- se a supor que a disponibilidade de $\mathrm{Pb}$ diminui com o tempo. $\mathrm{O}$ $\mathrm{pH}$ aparentemente não influiu na disponibilidade de $\mathrm{Pb}$ no solo.
As máximas extrações de cádmio aos 30 e 60 dias (Figura 3), cerca de $71,5 \mathrm{mg} \mathrm{dm}^{-3}$ e $26 \mathrm{mg}$ $\mathrm{dm}^{-3}$, respectivamente, resultaram da combinação de $0 \mathrm{mg} \mathrm{dm}^{-3}$ de silício com 360 e $720 \mathrm{mg} \mathrm{dm}^{-3}$ de fósforo. De modo geral, aumento nas doses de silício provocou reduções dos níveis extraídos de $\mathrm{Cd}$, até a dose $8.568 \mathrm{mg} \mathrm{dm}^{-3}$ de silício, a partir da qual aumentou a quantidade extraída. Entre todas as doses de fósforo utilizadas, a de $720 \mathrm{mg} \mathrm{dm}^{-3}$ provocou o incremento nos teores de Cd extraídos aos 60 dias, independente da dose de silício com ela combinada. Ao contrário do $\mathrm{Pb}$, parece que os teores de $\mathrm{Cd}$ foram influenciados pelo $\mathrm{pH}$, já que os mínimos extraídos coincidiram com valores de $\mathrm{pH}$ entre 7,0 e 8,0 (Figura 1), ou seja, nesses níveis de $\mathrm{pH}$, boa parte do $\mathrm{Cd}$ teria precipitado como fosfato, segundo Ayati \& Madsen, (2001), permanecendo nessa forma mesmo sob a ação de um extrator duplo ácido. Essas observações concordam com experiências de Chlopecka et al. (1996), as quais mostraram que os teores desse elemento no solo são muito suceptíveis às oscilações de $\mathrm{pH}$, e que o mesmo tende a se adsorver fortemente à matéria orgânica e aos óxidos de $\mathrm{Fe}$ e $\mathrm{Al}$ da fração argila, naqueles valores de $\mathrm{pH}$ (McBride, 1994); essa pode ser outra possível causa dos teores mais baixos de $\mathrm{Cd}$ encontrados entre $\mathrm{pH}$ 7,0 e 8,0. A dose $720 \mathrm{mg} \mathrm{dm}^{-3}$ de fósforo aos 30 dias não permitiu ajuste matemático.
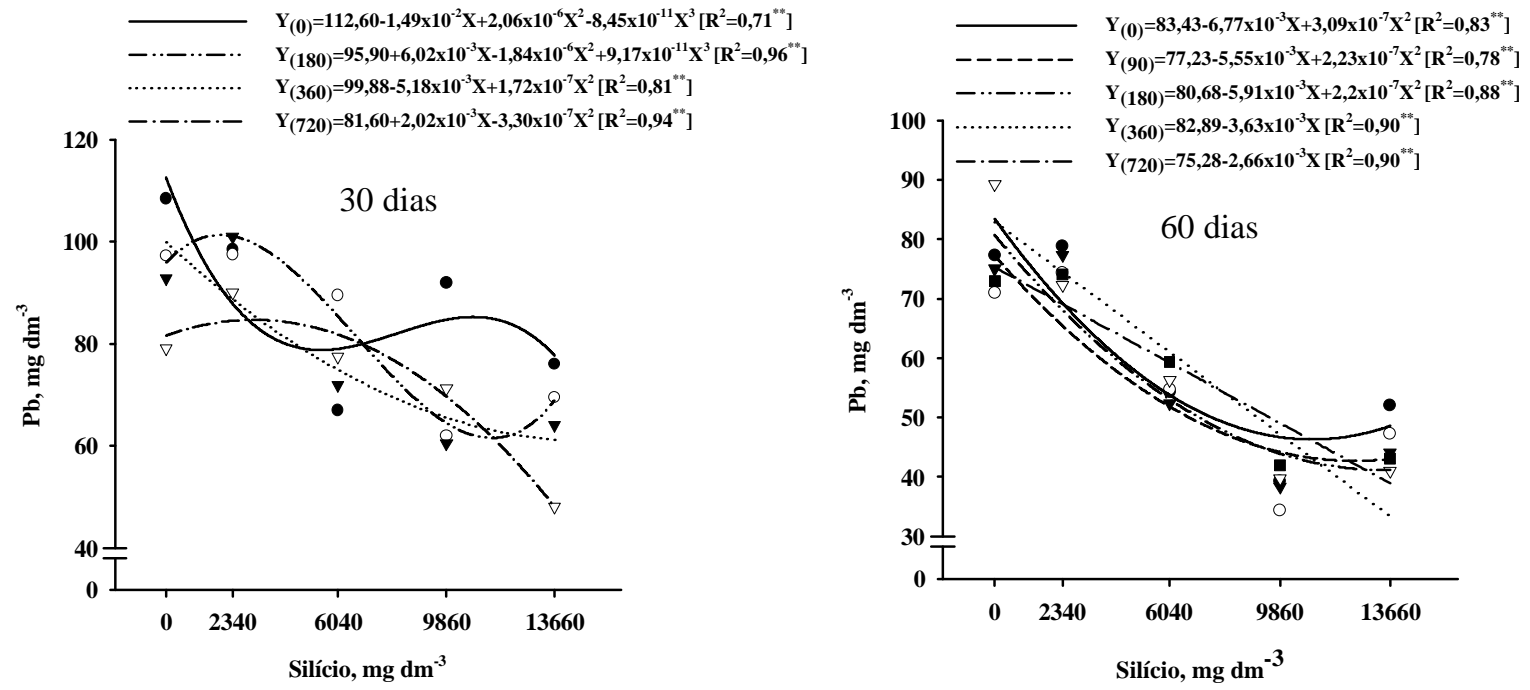

FIGURA 2 - Teores de Pb extraídos pelo Mehlich-1 de amostras de solo contaminado por metais pesados, em função das doses de silício e de fósforo $\left(\mathrm{mg} \mathrm{dm}^{-3}\right)$, em duas diferentes épocas. 

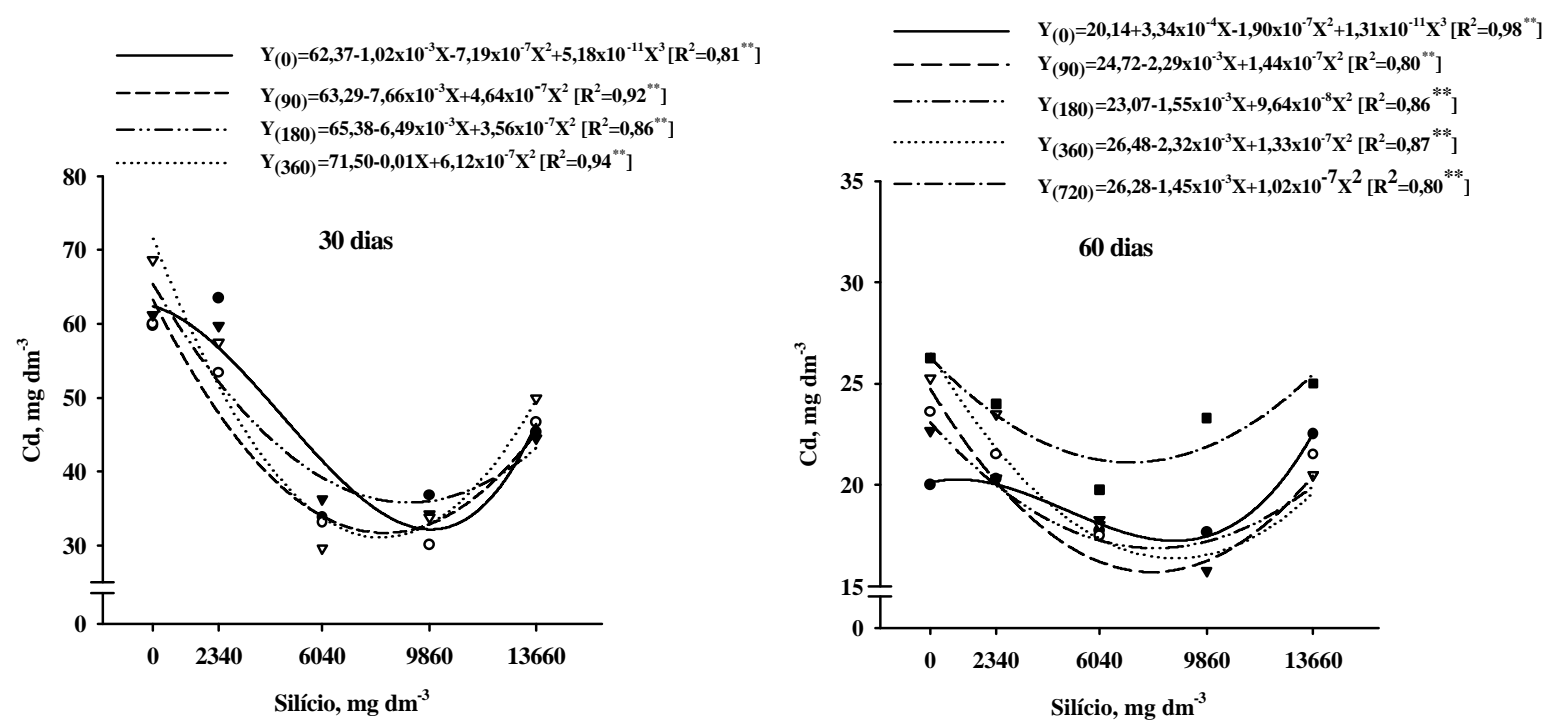

FIGURA 3 - Teores de Cd extraídos pelo Mehlich-1 de amostras de solo contaminado por metais pesados, em função das doses de silício e de fósforo $\left(\mathrm{mg} \mathrm{dm}^{-3}\right)$, em duas diferentes épocas.

A menor quantidade de cobre extraída aos 30 dias (Figura 4), cerca de $18,3 \mathrm{mg} \mathrm{dm}^{-3}$, resultou da combinação de $5.395 \mathrm{mg} \mathrm{dm}^{-3}$ de silício com $90 \mathrm{mg} \mathrm{dm}^{-3} \mathrm{de}$ fósforo. Com $13.660 \mathrm{mg} \mathrm{dm}^{-3}$ de silício associados a 0 , 180, 360 e $720 \mathrm{mg} \mathrm{dm}^{-3}$ de fósforo, os teores de $\mathrm{Cu}$ oscilaram entre 20 e $27 \mathrm{mg} \mathrm{dm}^{-3}$ de $\mathrm{Cu}$. Infere-se que o fósforo, muito mais que o $\mathrm{pH}$, influiu na disponibilidade do metal. Parece, nesse caso, que a reação do fósforo com o $\mathrm{Cu}$ resultou num composto mais móvel (solúvel) e, portanto, mais facilmente extraível pelo Mehlich-1.

Aos 60 dias, o máximo extraído, cerca de 21,3 $\mathrm{mg} \mathrm{dm}^{-3}$, resultou de $0 \mathrm{mg} \mathrm{dm}^{-3}$ de silício com $720 \mathrm{mg}$ $\mathrm{dm}^{-3}$ de fósforo. Por outro lado, a diminuição na quantidade de $\mathrm{Cu}$ extraída pode ser, de acordo com McBride (1994), decorrência de sua fácil adsorção aos óxidos de Fe e Al da fração argila, bem como a sua complexação a grupos ligantes contidos na matéria orgânica. $\mathrm{O}$ teor mínimo de $\mathrm{Cu}$, cerca de $15,6 \mathrm{mg} \mathrm{dm}^{-3}$, referente a $9.308 \mathrm{mg} \mathrm{dm}^{-3}$ de silício com $90 \mathrm{mg} \mathrm{dm}^{-3}$ de fósforo, coincidiu com o incremento de $\mathrm{pH}$ verificado na Figura 1. Esse fato, segundo ainda McBride (1994), estabelece as condições de baixa solubilidade do $\mathrm{Cu}$.

Há outras prováveis justificativas para a queda acentuada do $\mathrm{Cu}$ extraído em função do aumento das doses de silício e de fósforo, fenômeno constatado também na Figura 4, referente aos 60 dias: (a) precipitação de fosfatos do tipo $\mathrm{Cu}_{3}(\mathrm{OH})_{3} \mathrm{PO}_{4}, \mathrm{CuNH}_{4} \mathrm{PO}_{4}$ ou CuOH$\mathrm{PO}_{4}$ (Ayati \& Madsen, 2001) e (b) combinação insolúvel do $\mathrm{Cu}^{+2}$ com elevadas concentrações do ânion silicato.
Nota-se que, para o zinco, aos 30 dias e aos 60 dias (Figura 5), o aumento das doses de silício combinadas com as de fósforo diminuiu os teores do metal até o valor máximo de $\mathrm{pH}$ (Figura 1). Os teores mínimos extraídos aos 30 dias e aos 60 dias, cerca de 1.350 e $948 \mathrm{mg} \mathrm{dm}^{-3}$, resultaram das combinações de 7.255 $\mathrm{mg} \mathrm{dm}^{-3}$ de silício com $0 \mathrm{mg} \mathrm{dm}^{-3}$ de fósforo e $9.762 \mathrm{mg} \mathrm{dm}^{-3}$ silício com $360 \mathrm{mg} \mathrm{dm}^{-3}$ de fósforo, respectivamente. Observa-se também que a referida dose de silício associada a 90, 180 e $360 \mathrm{mg} \mathrm{dm}^{-3}$ de fósforo também proporcionou teores menores que o zero de fósforo aos 60 dias. Sugere-se, com isso, precipitação de fosfato de zinco (Carvalho, 1999).

Aos 30 e 60 dias, a combinação de $0 \mathrm{mg} \mathrm{dm}^{-3}$ de silício com quaisquer doses de fósforo resultou em teores de $\mathrm{Zn}$ extraídos maiores que o do tratamentocontrole, ou seja, cerca de $1.887 \mathrm{mg} \mathrm{dm}^{-3}$ aos 30 dias e $1.301 \mathrm{mg} \mathrm{dm}^{-3}$ de $\mathrm{Zn}$ aos 60 dias. Isto sugere que o pH influiu muito mais do que o fósforo na disponibilidade do Zn extraído, o que está coerente com o fato de que esse possui alta mobilidade em solos com baixos valores de $\mathrm{pH}$, principalmente em suas formas trocáveis (McBride, 1994). Entretanto, demonstra que, na ausência de silício, o fósforo aumentou a disponibilidade do $\mathrm{Zn}$, principalmente aos 30 dias. Fato semelhante também ocorreu com outros metais. Sugere-se que possíveis formas de $\mathrm{Zn}$ precipitadas como fosfatos insolúveis tornaram-se lábeis o suficiente para disponibilizar o elemento na solução do extrator devido ao baixo valor de $\mathrm{pH}$.

Ciênc. agrotec., Lavras. V.27, n.4, p.780-787, jul./ago., 2003 

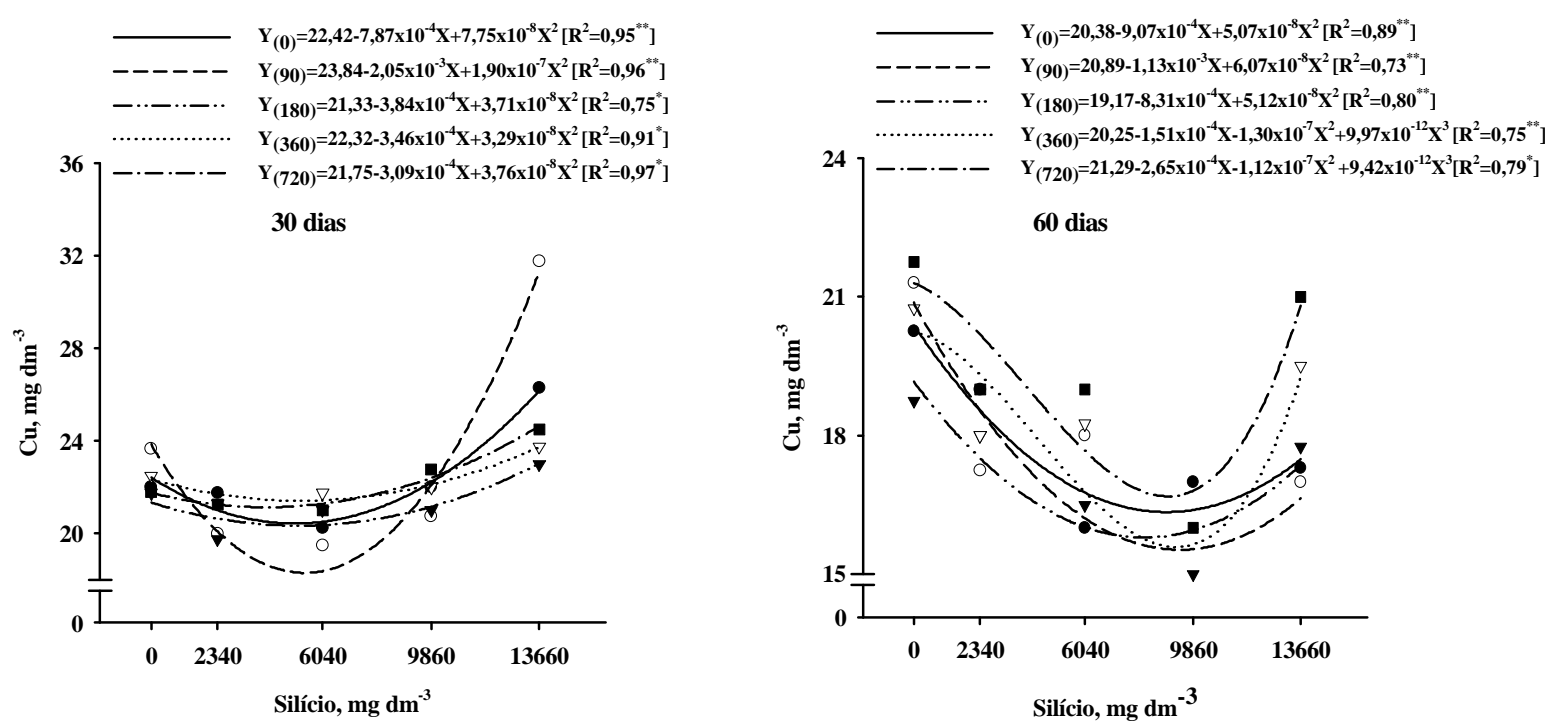

FIGURA 4 - Teores de Cu extraídos pelo Mehlich-1 de amostras de solo contaminado por metais pesados, em função das doses de silício e de fósforo $\left(\mathrm{mg} \mathrm{dm}^{-3}\right)$, em duas diferentes épocas.
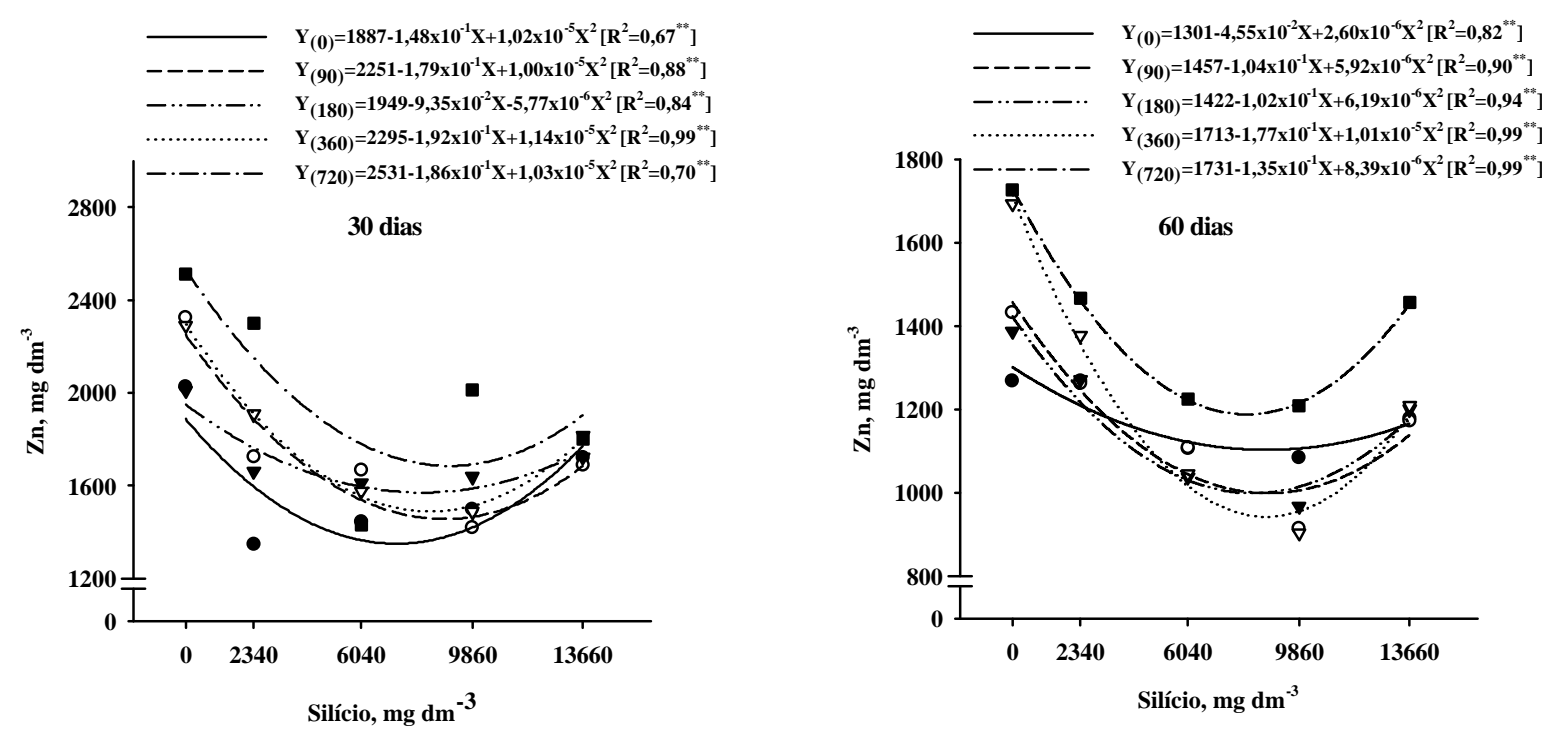

FIGURA 5 - Teores de Zn extraídos pelo Mehlich-1 de amostras de solo contaminado por metais pesados, em função das doses de silício e de fósforo $\left(\mathrm{mg} \mathrm{dm}^{-3}\right)$, em duas diferentes épocas.

Mesmo havendo, de modo geral, reduções nos teores de metais pesados, o $\mathrm{Zn}$ e $\mathrm{Cd}$ ainda mantiveramse superiores aos níveis permitidos para solos. Para o $\mathrm{Pb}$, os teores diminuiram com os tratamentos, tornan- do-se inferiores aos níveis permitidos. Quanto ao $\mathrm{Cu}$, não se pode afirmar o mesmo: os extratos obtidos chegaram a apresentar valores menores que os permitidos, segundo critérios da Comunidade Econômica Européia.

Ciênc. agrotec., Lavras. V.27, n.4, p.780-787, jul./ago., 2003 


\section{CONCLUSÕES}

a) A maior influência nos teores dos metais extraídos por Mehlich-1 foi do silício, do fósforo e do $\mathrm{pH}$.

b) A interação do silício com o fósforo contribuiu para diminuir a disponibilidade dos metais pesados no solo.

c) Apesar de o teor de metais pesados ter sido reduzido com a aplicação de silicato, $\mathrm{Zn}$ e Cd permaneceram em níveis superiores aos permitidos para solos. Para o $\mathrm{Pb}$, os teores diminuíram com os tratamentos, tornando-se inferiores aos níveis permitidos pela Comunidade Econômica Européia.

\section{REFERÊNCIAS BIBLIOGRÁFICAS}

ABREU, C. A.; ABREU, M. F.; RAIJ, B. Van; SANTOS, W. R. Comparação de métodos de análise para avaliar a disponibilidade de metais pesados em solos. Revista Brasileira de Ciência do Solo, Campinas, v. 19, n. 3, p. 463-468, set./dez. 1995.

AYATI, M.; MADSEN, H. E. L. Crystallization of some heavy metal phosphates alone and in the presence of calcium ion. Journal of Crystal Growth, Amsterdam, v. 208, n. 1/4, p. 579-591, Jan. 2001. Disponível em: <http//www.periódicos.-capes.gov.br.>. Acesso em: 20 set. 2001.

CARVALHO, R. Dessorção de fósforo por silício em um Cambissolo e um Latossolo vermelho escuro cultivado em eucalipto em casa de vegetação. 1999. 89 p. Tese (Doutorado em Solos e Nutrição de Plantas) Universidade Federal de Lavras, Lavras, 1999.

CHANDER, K.; BROOKES, P. C. Effects of heavy metals from past applications of sewage sludge on microbial biomass and organic matter accumulation in a sandy loam and silty loam U. K. soil. Soil Biology and Biochemistry, Oxford, v. 23, n. 10, p. 927-932, Oct. 1991.

CHANDER, K.; BROOKES, P. C. Residual effects of zinc, copper and nickel in sewage sludge on microbial biomass in a sandy loam. Soil Biology Biochemistry, Oxford, v. 25, n. 9, p. 1231-1239, Sept. 1993.

CHLOPECKA, A.; BACON, J. R.; WILSON, M. J.; KAY, J. Forms of cadmiun, lead an zinc in contaminated soils from southwest poland. Journal of Environmental Quality, Madison, v. 25, n. 1, p. 69-79, Jan./Feb. 1996.
EMPRESA BRASILEIRA DE PESQUISA AGROPECUÁRIA. Centro Nacional de Pesquisa de Solos. Manual de métodos de análise de solo. 2 . ed. Rio de Janeiro: Ministério da Agricultura e abastecimento, 1997. $212 \mathrm{p}$.

EMPRESA BRASILEIRA DE PESQUISA AGROPECUÁRIA. Serviço Nacional de Levantamento e Conservação de Solos. Manual de métodos de análise do solo. Rio de Janeiro, 1979.

FREIRE, J. C.; RIBEIRO, M. A. V.; BAHIA, V. G.; LOPES, A. S.; AQUINO, L. H. Resposta do milho cultivado em casa de vegetação a níveis de água em solos da região de Lavras (MG). Revista Brasileira de Ciência do Solo, Campinas, v. 4, n. 1, p. 5-8, jan./abr. 1980.

GOMES, P. C.; FONTES, M. P. F.; COSTA, L. M.; MENDONÇA, E. S. Extração fracionada de metais pesados em Latossoso Vermelho-Amarelo. Revista Brasileira de Ciência do Solo, Campinas, v. 21, n. 4, p. 543-551, out./dez. 1997.

HINGSTON, F. J.; POSNER, A. M.; QUIRK, J. P. Anion adsorption by goethite and gibbsite. I. The role of the proton in determining adsorptions envelopes. Journal of Soil Science, Oxford, v. 23, n. 2, p. 177-192, June 1972.

HUHEEY, J. E.; KEITER, E. A.; KEITE, R. L. Inorganic chemistry, principles of structure and reactivity. 4. ed. Harper Collins College Publisbers, 1993. $964 \mathrm{p}$

JOLY, W. L. A química dos não metais. São Paulo: Berkeley, 1966. 176 p.

KORCAK, R. F.; FANNING, D. S. Extractability of cadmium, copper, nickel and zinc by double acid versus DTPA and plant content at excessive soil levels. Journal Environmental Quality, Madison, v. 7, n. 4, p. 506-512, 1978.

LINDSAY, W. L. Chemical equilibria in soils. New York: John Wiley, 1979. 449 p.

LINDSAY, W. L.; NORVELL, W. A. Development of DTPA soil test for zinc, iron, manganese and cooper. Soil Science Society of America Journal, Madison, v. 42, n. 3, p. 421-428, May/June 1978. 
MARTINEZ, C. E.; MOTTO, H. L. Solubility of lead, zinc and copper added to mineral soils. Environmental Pollutin, London, v. 107, n. 1, p. 153-158, 2000. Disponível em: <http//www.periódicos.-capes.gov.br>. Acesso em: 25 set. 2001.

McBRIDE, M. D. Environmental chemistry of soils. New York: Oxford University, 1994. 406 p.

MEHRA, O. P.; JACKSON, M. L. Iron oxide removal from soil and clays by a dithionite-citrate system buffered with sodium bicarbonate. Clays and Minerals, New York, v. 7, p. 317-327, 1960.

RIBEIRO FILHO, M. R.; CURI, N.; SIQUEIRA, J. O.; MOTTA, P. E. F. Metais pesados em solos de área de rejeitos de indústria de processamento de zinco. Revista Brasileira de Ciência do Solo, Viçosa, v. 23, n. 2, p. 453-464, abr./jun. 1999.

ROY, A. C.; ALI, M. V.; FOX, R. L.; SILVA, J. A. Influence of calcium silicate on phosphate solibility and availability in Hawaian Latossols. In: SYMPOSIUM ON SOIL
FERTILITY AND EVALUATION, 1971, Honolulu. Proceedings... New Delhi: [s.n.], 1971. p. 756-765.

SIMÃO, J. B. P. Mitigação da fitotoxidez de metais pesados no solo, através do uso de materiais orgânicos e inorgânicos. 1999. 135 p. Tese (Doutorado em Solos e Nutrição de Plantas) - Universidade Federal de Lavras, Lavras, 1999.

SYERS, J. K.; BROWMAN, M. G.; SAMILLE, G. W.; COREY, R. B. Phosphate sortion by soils evaluated by the langmuir adsorption equation. Soil Science Society America Proceedings, Madison, v. 37, n. 3, p. 358363, May/June 1973.

VETTORI, L. Métodos de análise do solo. Rio de Janeiro: [s.n.], 1969. 34 p. (Boletim Técnico, 7).

VOLKWEISS, S. J.; RAIJ, B. van. Retenção e disponibilidade de fósforo em solos. In: SIMPÓSIO SOBRE CERRADO, BASES PARA UTILIZAÇÃO AGROPECUÁRIA, 4., 1976, Brasília. Anais... São Paulo: EDUSP, 1977. p. 317-332. 